\title{
Застосування елементів хореографії в тренувальному процесі спортсменок-початківців для успішного освоєння програм з художньої гімнастики
}

\section{Ольга Рябченко}

Харківська державна академія фізичної культури, Харків, Україна

\begin{abstract}
Мета: застосувати хореографічну підготовку в тренувальний процес спортсменок-початківців та визначити їі вплив на виконання базових вправ з художньої гімнастики.

Матеріал і методи: педагогічний експеримент проводився на базі КЗ «КДЮСШ №1 ХМР» серед спортсменокпочатківців 5-6 років. У дослідженні брали участь 24 гімнастки: контрольна група (n=12) проводила тренувальний процес за програмою ДЮСШ, експериментальна $(n=12)$ - із додатковим застосуванням хореографічної підготовки. Для оцінювання артистичних та технічних компонентів були залучені 2 хореографи з суддівським досвідом та 4 тренери національної категорії. Через те, що рівень підготовленості юних спортсменок знаходився на початковому етапі, була застосована 5-ти бальна шкала оцінки. Перше оцінювання виконання базових вправ з художньої гімнастики юних спортсменок проводилось в досліджуваних групах на початку навчального року, друге - наприкінці півріччя.

Результати: у процесі застосовування хореографічних вправ для освоєння програм з художньої гімнастики спортсменок-початківців 5-6 років експериментальної групи отримано достовірно кращі результати оцінювання, по відношенню до контрольної групи, у виконанні компонентів: «виразність руху тіла» $(t=4,97 ; p<0,001)$, «рівноваги» $(t$ $=4,48 ; p<0,001)$, «характер» $(t=3,71 ; p<0,01)$, «ритм» $(t=4,18 ; p<0,01)$, «стрибки» $(t=3,22 ; p<0,01)$ та «повороти» $(t=3,77 ; p<0,01)$.

Висновки: у результаті досліджень встановлено, що додаткове застосування хореографії в тренувальному процесі спортсменок-початківців 5-6 років ефективно впливає на виконання базових вправ з художньої гімнастики, що свідчить про успішне освоєння програм в цьому виді спорту. Саме під час цих занять відбувається формування осанки, зміцнення опорно-рухового апарату та формується культура рухів гімнасток.
\end{abstract}

Ключові слова: художня гімнастика, хореографія, спортсменки початківці, артистична підготовленість.

\section{Вступ}

Художня гімнастика - надзвичайно жіночний вид спорту, своєрідна комбінація атлетизму з артистичністю та музикою. У цій дисципліні важливу складову відіграє вибір ряду компонентів: артистичні - характер, ритм, динамічні зміни, виразність руху тіла та технічні - стрибки, повороти, рівноваги і преакробатичні елементи [8]. Проте в тренувальному процесі спортсменок-початківців, які займаються художньою гімнастикою, спостерігається недостатній рівень засвоєння цих компонентів. Адже окрім технічного виконання програми та рівня складності, судді також оцінюють артистизм і хореографію.

Зараз хореографія стала невід'ємною складовою для підготовки гімнасток високого рівня і чим раніше починаються ці заняття, тим кращий результат буде досягнуто [5]. За Мартиненко О. В., ознайомлення дітей дошкільного віку з класичним танцем сприяє правильній поставі тулуба, рук та ніг, зміцненню м'язів тіла, розвитку музично-рухової координації, усвідомленню естетики і краси хореографічних рухів [4]. Кизім П. М. у своїй науковій роботі говорить, що застосування сучасних напрямків хореографії у підготовці юних спортсменок має місце, але застосування рухів народно-сценічного танцю здебільшого не прослідковується [2].

Отже, аналіз спеціальної науково-методичної літератури порушує тему важливості занять хореографією в тренувальному процесі спортсменок-початківців, які займаються художньою гімнастикою.

Мета дослідження - застосувати хореографічну підготовку в тренувальний процес спортсменок-початківців та визначити її вплив на виконання базових вправ з художньої гімнастики. 


\section{СЛОБОЖАНСЬКИЙ НАУКОВО-СПОРТИВНИЙ ВІСНИК}

\section{Матеріал і методи дослідження}

Педагогічний експеримент проводився на базі КЗ «КДЮСШ №1 ХМР» серед спортсменок-початківців 5-6 років. У дослідженні брали участь 24 гімнастки: контрольна група $(\mathrm{n}=12)$ проводила тренувальний процес за програмою ДЮСШ, експериментальна $(n=12)$ - із додатковим застосуванням хореографічної підготовки. Для оцінювання артистичних та технічних компонентів були залучені 2 хореографи з суддівським досвідом та 4 тренери національної категорії. Через те, що рівень підготовленості юних спортсменок знаходився на початковому етапі, була застосована 5-ти бальна шкала оцінки. Перше оцінювання виконання базових вправ 3 художньої гімнастики юних спортсменок проводилось в досліджуваних групах на початку навчального року, друге - наприкінці півріччя.

Зв'язок дослідження 3 науковими чи практичними завданнями, планами, програмами. Дослідження виконано відповідно до ініціативної теми НДР кафедри гімнастики, танцювальних видів спорту та хореографії ХДАФК: «Теоретико-методологічні основи розвитку системо-утворюючих компонентів фізичної культури (спорт, фітнес і рекреація)» на 2020-2025 рр. (номер державної реєстрації 0120U01215).

\section{Результати дослідження}

Дослідження проводилось тривалістю один навчальний семестр. Експериментальна група тренувалась тричі на тиждень по дві години: одна година відводилась загальній підготовці гімнасток за програмою
ДЮСШ [7], а друга година складалася 3 хореографії біля станку та на середині зали. Заняття хореографією включало в себе стандартну хореографічну підготовку для спортсменок-початківців. Контрольна група займалась також тричі на тиждень по дві години, але весь час був присвячено загальній підготовці з художньої гімнастики. Результати початкового оцінювання приведені в таблицях 1 та 2.

На початку дослідження передбачалося, що для поліпшення показників спортсменок початківців 5-6 років, які змагаються за програмою з художньою гімнастики КДЮСШ, використовувалася експериментальна методика. За час впровадження вправ з хореографії в експериментальній групі підвищилися показники як артистичних, так і технічних якостей юних спортсменок, які суттєво впливають на виконання базових вправ з художньої гімнастики. Статистичні результати тестування в кінці педагогічного експерименту наведено у таблицях 3, 4 .

Найбільш суттєві $(p<0,001)$ позитивні зрушення, отримані в показниках виразність руху тіла та рівновагах. В абсолютному значенні показники поліпшились на $33 \%$ та 25\%. Це дає привід казати, що хореографічна підготовка цілковито сприяє кращим та більш координованим рухам тіла у поєднанні з рівновагою.

У меншій мірі $(p<0,01)$ покращилися показники у компонентах оцінювання характеру $(\mathrm{t}=3,71)$ - середній бал збільшився на 0,8 балів; ритму $(t=4,18)$ - середній бал збільшився на 0,9 балів; стрибку $(t=3,22)$ - середній бал збільшився на 0,6 балів та поворотів $(\mathrm{t}=3,77)$ - середній бал збільшився на 0,9 балів. Також були

Таблиця 1

Результати оцінювання експериментальної групи на початку педагогічного експерименту, бали

\begin{tabular}{|c|c|c|c|c|c|c|c|c|}
\hline \multirow{2}{*}{ 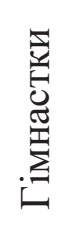 } & \multicolumn{4}{|c|}{$\begin{array}{c}\text { Артистичні компоненти } \\
\text { оцінювання, бали }\end{array}$} & \multicolumn{4}{|c|}{$\begin{array}{c}\text { Технічні компоненти } \\
\text { оцінювання, бали }\end{array}$} \\
\hline & Характер & Ритм & $\begin{array}{l}\text { Динамічні } \\
\text { зміни }\end{array}$ & $\begin{array}{l}\text { Виразність } \\
\text { руху тіла }\end{array}$ & Стрибки & Повороти & Рівноваги & $\begin{array}{l}\text { Преакробатичні } \\
\text { елементи }\end{array}$ \\
\hline 1 & 4 & 4 & 4 & 4 & 3 & 3 & 3 & 4 \\
\hline 2 & 3 & 4 & 3 & 3 & 4 & 3 & 4 & 4 \\
\hline 3 & 4 & 5 & 4 & 4 & 4 & 3 & 4 & 3 \\
\hline 4 & 4 & 3 & 3 & 3 & 2 & 3 & 3 & 3 \\
\hline 5 & 3 & 4 & 3 & 3 & 4 & 3 & 4 & 3 \\
\hline 6 & 4 & 4 & 5 & 3 & 3 & 4 & 4 & 4 \\
\hline 7 & 3 & 4 & 4 & 3 & 3 & 3 & 4 & 3 \\
\hline 8 & 4 & 3 & 2 & 3 & 4 & 3 & 4 & 3 \\
\hline 9 & 4 & 3 & 4 & 4 & 3 & 3 & 3 & 3 \\
\hline 10 & 3 & 4 & 3 & 3 & 3 & 4 & 4 & 5 \\
\hline 11 & 4 & 4 & 4 & 3 & 4 & 3 & 4 & 4 \\
\hline 12 & 3 & 4 & 3 & 4 & 4 & 5 & 4 & 3 \\
\hline $\bar{X}$ & 3,58 & 3,83 & 3,50 & 3,33 & 3,42 & 3,33 & 3,75 & 3,50 \\
\hline$m$ & 0,16 & 0,17 & 0,24 & 0,15 & 0,20 & 0,20 & 0,14 & 0,20 \\
\hline
\end{tabular}




\section{СЛОБОЖАНСЬКИЙ НАУКОВО-СПОРТИВНИЙ ВІСНИК}

Таблиця 2

Результати оцінювання контрольної групи на початку педагогічного експерименту, бали

\begin{tabular}{|c|c|c|c|c|c|c|c|c|}
\hline \multirow{2}{*}{ 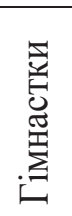 } & \multicolumn{4}{|c|}{$\begin{array}{c}\text { Артистичні компоненти } \\
\text { оцінювання, бали }\end{array}$} & \multicolumn{4}{|c|}{$\begin{array}{c}\text { Технічні компоненти } \\
\text { оцінювання, бали }\end{array}$} \\
\hline & Характер & Ритм & $\begin{array}{c}\text { Динамічні } \\
\text { зміни }\end{array}$ & $\begin{array}{c}\text { Виразність } \\
\text { руху тіла }\end{array}$ & Стрибки & Повороти & Рівноваги & $\begin{array}{l}\text { Преакробатичні } \\
\text { елементи }\end{array}$ \\
\hline 1 & 3 & 4 & 3 & 4 & 4 & 4 & 4 & 4 \\
\hline 2 & 5 & 3 & 4 & 4 & 4 & 3 & 4 & 3 \\
\hline 3 & 3 & 3 & 4 & 3 & 4 & 4 & 4 & 4 \\
\hline 4 & 4 & 3 & 3 & 4 & 4 & 3 & 3 & 4 \\
\hline 5 & 4 & 3 & 3 & 3 & 4 & 3 & 4 & 3 \\
\hline 6 & 3 & 4 & 4 & 3 & 3 & 2 & 3 & 3 \\
\hline 7 & 3 & 3 & 2 & 3 & 4 & 4 & 3 & 4 \\
\hline 8 & 4 & 3 & 3 & 3 & 3 & 3 & 3 & 4 \\
\hline 9 & 3 & 3 & 4 & 4 & 4 & 5 & 4 & 3 \\
\hline 10 & 3 & 4 & 3 & 4 & 3 & 3 & 4 & 4 \\
\hline 11 & 4 & 3 & 4 & 3 & 4 & 4 & 4 & 5 \\
\hline 12 & 3 & 3 & 3 & 2 & 4 & 3 & 3 & 3 \\
\hline $\bar{X}$ & 3,5 & 3,25 & 3,33 & 3,33 & 3,75 & 3,42 & 3,58 & 3,67 \\
\hline$m$ & 0,20 & 0,14 & 0,20 & 0,20 & 0,14 & 0,24 & 0,16 & 0,20 \\
\hline
\end{tabular}

Таблиця 3

Статистичні показники підготовленості гімнасток експериментальної групи педагогічного експерименту (n=12), бали

\begin{tabular}{|c|c|c|c|c|c|}
\hline \multirow{3}{*}{ Компоненти } & \multirow{3}{*}{$\begin{array}{c}\text { Складові компонентів } \\
\text { оцінювання }\end{array}$} & \multicolumn{2}{|c|}{$\begin{array}{c}\text { Експериментальна група } \\
\text { (n=12) }\end{array}$} & \multirow{3}{*}{$t_{e}$} & \multirow{3}{*}{$\mathrm{p}$} \\
\hline & & на початку & після & & \\
\hline & & \multicolumn{2}{|c|}{$\bar{X} \pm m$, бали } & & \\
\hline \multirow{4}{*}{ 胥 } & Характер & $3,58 \pm 0,16$ & $4,42 \pm 0,16$ & 3,71 & $<0,01$ \\
\hline & Ритм & $3,83 \pm 0,17$ & $4,75 \pm 0,14$ & 4,18 & $<0,01$ \\
\hline & Динамічні зміни & $3,50 \pm 0,24$ & $4,33 \pm 0,23$ & 2,50 & $<0,05$ \\
\hline & Виразність руху тіла & $3,33 \pm 0,15$ & $4,42 \pm 0,16$ & 4,97 & $<0,001$ \\
\hline \multirow{4}{*}{. } & Стрибки & $3,42 \pm 0,20$ & $4,00 \pm 0,20$ & 3,22 & $<0,01$ \\
\hline & Повороти & $3,33 \pm 0,20$ & $4,25 \pm 0,14$ & 3,77 & $<0,01$ \\
\hline & Рівноваги & $3,75 \pm 0,14$ & $4,67 \pm 0,15$ & 4,48 & $<0,001$ \\
\hline & $\begin{array}{l}\text { Преакробатичні } \\
\text { елементи }\end{array}$ & $3,50 \pm 0,20$ & $4,33 \pm 0,20$ & 2,93 & $<0,05$ \\
\hline
\end{tabular}

позитивні зміни $(p<0,05)$ і в таких показниках, як динамічні зміни $(t=2,50)$ та преакробатичні елементи $(t$ $=2,93)-$ середній бал цих показників збільшився на 0,8 балів. Зазначене свідчить, що застосування хореографії в тренувальному процесі відповідно до кожної вправи дозволяє підвищити якість виконання базових елементів художньої гімнастики на етапі початкової підготовки.
У той же час динаміка змін оцінки компонентів виконання змагальної програми на початку та після педагогічного дослідження в контрольній групі висвітлена в наступних результатах: експертна оцінка компоненту «характер» в групі у відсотковому співвідношенні зросла на 2,3\% ( $t=0,31 ; p>0,05)$, компоненту «ритм» - на $5,2 \%(t=0,80 ; p>0,05)$, компоненту «динамічні зміни» - на $5,1 \%(t=0,54 ; p>0,05)$, компоненту «стрибки» - на 


\section{Статистичні показники підготовленості гімнасток контрольної групи педагогічного експерименту $(\mathrm{n}=12)$, бали}

\begin{tabular}{|c|c|c|c|c|c|}
\hline \multirow{3}{*}{ Компоненти } & \multirow{3}{*}{$\begin{array}{c}\text { Складові компонентів } \\
\text { оцінювання }\end{array}$} & \multicolumn{2}{|c|}{$\begin{array}{c}\text { Контрольна група } \\
(\mathrm{n}=12)\end{array}$} & \multirow{3}{*}{$t_{e}$} & \multirow{3}{*}{$\mathrm{p}$} \\
\hline & & на початку & після & & \\
\hline & & \multicolumn{2}{|c|}{$\overline{\bar{X}} \pm m$, бали } & & \\
\hline \multirow{4}{*}{ 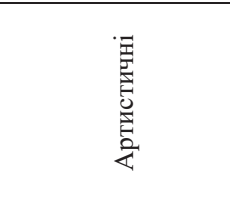 } & Характер & $3,50 \pm 0,20$ & $3,58 \pm 0,16$ & 0,31 & $>0,05$ \\
\hline & Ритм & $3,25 \pm 0,14$ & $3,42 \pm 0,16$ & 0,80 & $>0,05$ \\
\hline & Динамічні зміни & $3,33 \pm 0,20$ & $3,50 \pm 0,24$ & 0,54 & $>0,05$ \\
\hline & Виразність руху тіла & $3,33 \pm 0,20$ & $3,25 \pm 0,14$ & 0,32 & $>0,05$ \\
\hline \multirow{4}{*}{ 壱 } & Стрибки & $3,75 \pm 0,14$ & $3,83 \pm 0,17$ & 0,36 & $>0,05$ \\
\hline & Повороти & $3,42 \pm 0,24$ & $3,50 \pm 0,20$ & 0,26 & $>0,05$ \\
\hline & Рівноваги & $3,58 \pm 0,16$ & $3,75 \pm 0,14$ & 0,79 & $>0,05$ \\
\hline & Преакробатичні елементи & $3,67 \pm 0,17$ & $3,5 \pm 0,16$ & 0,60 & $>0,05$ \\
\hline
\end{tabular}

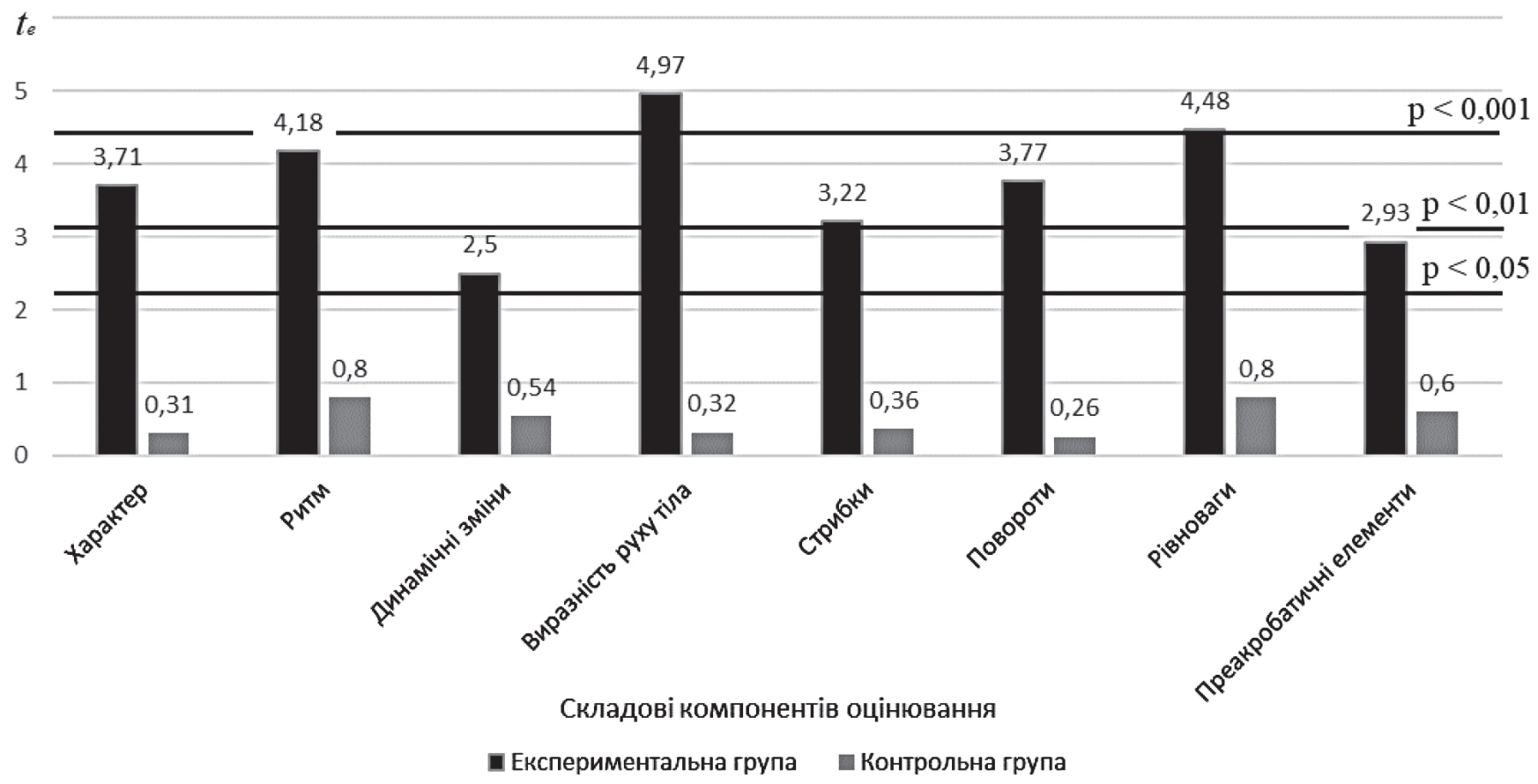

Рис. 1. Достовірність показників рівня підготовленості гімнасток контрольної та експериментальної груп після педагогічного експерименту

$2,1 \%(t=0,36 ; p>0,05)$, компоненту «повороти» - на 2,3\% ( $\mathrm{t}=0,26 ; \mathrm{p}>0,05)$, компоненту «рівноваги» - на 4,7\% $(t=0,79 ; p>0,05)$. Але експертна оцінка таких компонентів як «виразність руху тіла» $(t=0,32 ; p>0,05)$ та «преакробатичні елементи» $(t=0,60 ; p>0,05)$ - зменшилась на 2,4\% та 4,6\% відповідно.

При проведенні порівняння показників рівня технічної та артистичної підготовленості гімнасток контроль- ної та експериментальної груп, спостерігається достовірність результатів у всіх складових компонентах оцінювання змагальної програми (рис. 1).

У порівняльній характеристиці середньостатистичної оцінки компонентів виконання змагальної програми спортсменками-початківцями з художньої гімнастики встановлено позитивну різницю на користь експериментальної групи. Відсоткове співвідношення 
Результати порівняння оцінок гімнасток контрольної та експериментальної груп, отриманих наприкінці педагогічного експерименту, бали

\begin{tabular}{|c|c|c|c|c|c|}
\hline \multirow[t]{2}{*}{ Компоненти } & \multirow{2}{*}{$\begin{array}{c}\text { Складові } \\
\text { компонентів } \\
\text { оцінювання }\end{array}$} & $\begin{array}{c}\text { Експериментальна } \\
\text { група }(\mathrm{n}=12)\end{array}$ & $\begin{array}{c}\text { Контрольна } \\
\text { група }(\mathrm{n}=12)\end{array}$ & \multirow[t]{2}{*}{$t_{e}$} & \multirow[t]{2}{*}{$\mathrm{p}$} \\
\hline & & \multicolumn{2}{|c|}{$\bar{X} \pm m$, бали } & & \\
\hline \multirow{4}{*}{ 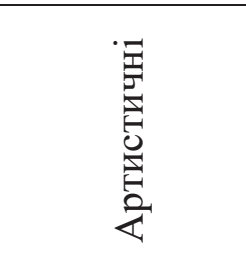 } & Характер & $4,42 \pm 0,16$ & $3,58 \pm 0,16$ & 3,71 & $<0,01$ \\
\hline & Ритм & $4,75 \pm 0,14$ & $3,42 \pm 0,16$ & 6,26 & $<0,001$ \\
\hline & Динамічні зміни & $4,33 \pm 0,23$ & $3,50 \pm 0,24$ & 2,50 & $<0,05$ \\
\hline & $\begin{array}{l}\text { Виразність руху } \\
\text { тіла }\end{array}$ & $4,42 \pm 0,16$ & $3,25 \pm 0,14$ & 5,50 & $<0,001$ \\
\hline \multirow{4}{*}{ 禀 } & Стрибки & $4,00 \pm 0,13$ & $3,83 \pm 0,17$ & 0,79 & $>0,05$ \\
\hline & Повороти & $4,25 \pm 0,14$ & $3,50 \pm 0,20$ & 3,07 & $<0,01$ \\
\hline & Рівноваги & $4,67 \pm 0,15$ & $3,75 \pm 0,14$ & 4,48 & $<0,001$ \\
\hline & $\begin{array}{l}\text { Преакробатичні } \\
\text { елементи }\end{array}$ & $4,33 \pm 0,20$ & $3,50 \pm 0,20$ & 2,93 & $<0,01$ \\
\hline
\end{tabular}

становить: контрольна група - 3,9\%. експериментальна група $-25 \%$.

В таблиці 5 наведено результати порівняння середніх балів гімнасток, отриманих в кінці педагогічного експерименту. В артистичних компонентах значно покращилися показники експериментальної групи - «ритм» $(t=6,26 ; p<0,001)$ та «виразність руху тіла» $(t=5,50 ;$ $\mathrm{p}<0,001)$, а в технічних компонентах - «рівноваги» $(\mathrm{t}=$ $4,48 ; p<0,001)$. Але, на жаль, не відбулося змін в оцінюванні технічного компоненту «стрибки» $(t=0,79 ; p>0,05)$.

\section{Висновки/ Дискусія}

Дослідження $з$ даної теми показало ряд наукових розробок та практичних заходів до впровадження в навчально-тренувальний процес методів та засобів хореографії у вдосконаленні технічної та артистичної підготовленості спортсменок, які займаються художньою гімнастикою.
Роль тренера з художньої гімнастики досить ясна, а ось роль хореографа досить складна - навчити дівчат красиво рухатися, правильно виконувати елементи танцю, долучити їх до культури рухів, до естетики жестів тощо.

Отримані нами результати свідчать, що застосовування хореографічних вправ наряду з базовими елементами художньої гімнастики дозволили підвищити результати спортсменок початківців 5-6 років експериментальної групи, по відношенню до контрольної групи, у виконанні компонентів: «виразність руху тіла» $(\mathrm{t}=4,97$; $\mathrm{p}<0,001)$, «рівноваги» $(\mathrm{t}=4,48 ; \mathrm{p}<0,001)$, «характер» $(\mathrm{t}$ $=3,71 ; \mathrm{p}<0,01)$, «ритм» $(\mathrm{t}=4,18 ; \mathrm{p}<0,01)$, «стрибки» $(\mathrm{t}=$ $3,22 ; p<0,01)$ та «повороти» $(t=3,77 ; p<0,01)$.

Отже, хореографія стала невід'ємною частиною підготовки спортсменок початківців 5-6 років і посідає не останнє місце в процесі тренувань $з$ художньої гімнастики. Саме під час цих занять відбувається формування осанки, укріплення опорно-рухового апарату та формується культура рухів гімнасток.

Конфлікт інтересів. Автори заявляють, що відсутній конфлікт інтересів, який може сприйматись таким, що може завдати шкоди неупередженості статті.

Джерела фінансування. Ця стаття не отримала фінансової підтримки від державної, громадської або комерційної організації.

\section{Список посилань}

1. Бекина С. И., Ломова Т. П., Соковнина Е. Н. (1983), Музыка и движение (упражнения, игры и пляски для детей 5-6 лет). М.: Просвещение, 208 с.

2. Кизім П., Батєєва Н. (2021), «Вдосконалення технічної підготовленості спортсменок художньої гімнастики засобами народно-сценічного танцю», Слобожанський науково-спортивний вісник, № 1(81), С. 36-41, doi:10.15391/snsv.2021-1.005

3. Лисицкая Т. С. (1984), Хореография в гимнастике. М.: ФИС, 175 с.

4. Мартиненко О. В. (2008), Методика хореографічної роботи з дітьми старшого дошкільного віку. Донецьк: ТОВ «ЮгоВосток, ЛТД», $156 \mathrm{c.}$

5. Муллагильдина А. Я. (2016), «Совершенствование артистичности у квалифицированных спортсменок в художественной гимнастике», Слобожанський науково-спортивний вісник, № 4(54). С. 79-83. doi:10.15391/ snsv. 4.014

6. Тараканова А. П. (1996), Система хореографічного виховання у школах та позашкільних навчальних закладах: навчально-методичний посібник. К.: Мін-во освіти України, 68 с. 
7. Художня гімнастика (1999), Навчальна програма для дитячо-юнацьких спортивних шкіл, спеціалізованих шкіл олімпійського резерву, шкіл вищої спортивної майстерності. Київ, 115 с.

8. Художественная гимнастика: правила соревнований 2017-2020 г. (2017), Технический комитет по художественной гимнастике, Международная федерация гимнастики, 82 с.

9. Riabchenko. O. V. (2015), «The formation of bases of culture of movement at children of 3-6 years old by means of rhythmic gymnastics», Slobozhanskii naukovo-sportyvnyi visnyk, No. 3 (47), pp. 80-81, doi.org/10.15391/snsv.2015-3

10. Morgan W. J. (2003), The Philosophy of Sport: A. Historical and Conoqtual Overview and Eric Dunning: handbook of Sports Studies. London: Sage, pp. 205-212.

11. Svobodovб L., Skotбkovб A., Hedbбvnэ P., Vaculнkovб P. \& Sebera M. (2016), «Use of the dance pad for the development of rhythmic abilities», Science of Gymnastics Journal, Vol. 8, Issue 3, pp. 283-293.

12. Poliszczuk R. (2003), Podstawy przygotowania choreograficznego w sporcie. Warszawa: Centralny Osrodek sportu, pp. $32-38$.

13. Kuzminska O. (1991), Podreczhik gimnasyki artystystycznej. Warszawa: Sport I Turystyka, p.384 .

Стаття надійшла до редакції: 20.05.2021 р.

Опубліковано: 23.06.2021 p.

\begin{abstract}
Аннотация. Ольга Рябченко. Применение элементов хореографии в тренировочном процессе начинающих спортсменок для успешного освоения программ по художественной гимнастике. Цель: применить хореографическую подготовку в тренировочный процесс начинающих спортсменок и определить ее влияние на выполнение базовых упражнений по художественной гимнастике. Материал и методы: педагогический эксперимент проводился на базе КЗ «КДЮСШ № 1 ХГС» среди начинающих спортсменок 5-6 лет. В исследовании принимали участие 24 гимнастки: контрольная группа (п=12) проводила тренировочный процесс по программе ДЮСШ, экспериментальная $(n=12)$ с дополнительным применением хореографической подготовки. Для оценки артистических и технических компонентов были привлечены 2 хореографа с судейским опытом и 4 тренера национальной категории. Так как уровень подготовленности юных спортсменок находился на начальном этапе, была применена 5-ти балльная шкала оценки. Первое оценивание выполнения базовых упражнений по художественной гимнастике юных спортсменок проводилось в исследуемых группах в начале учебного года, второе - в конце полугодия. Результаты: в процессе применения хореографических упражнений для освоения программ по художественной гимнастике начинающих спортсменок 5-6 лет экспериментальной группы, получено достоверно лучшие результаты оценивания по отношению к контрольной группе в выполнении компонентов: «выразительность движения тела» $(t=4,97 ; p<0,001)$, «равновесия» $(t=4,48 ; p$ $<0,001)$, «характер» $(t=3,71 ; p<0,01)$, «ритм» $(t=4,18 ; p<0,01)$, «прыжки» $(t=3,22 ; p<0,01)$ и «повороты» $(t=3,77 ; p<0,01)$. Выводы: в результате исследований установлено, что дополнительное применение хореографии в тренировочном процессе начинающих спортсменок 5-6 лет эффективно влияет на выполнение базовых упражнений по художественной гимнастике, что свидетельствует об успешном освоении программ в этом виде спорта. Именно во время этих занятий происходит формирование осанки, укрепление опорно-двигательного аппарата и формируется культура движений гимнасток.
\end{abstract} ность.

ключевые слова: художественная гимнастика, хореография, начинающие спортсменки, артистическая подготовлен-

Abstract. Olga Riabchenko. Use of choreography elements in the training process of novice athletes for the successful development of rhythmic gymnastics programs. Purpose: apply choreographic training in the training process of novice athletes and determine its influence on the performance of basic rhythmic gymnastics exercises. Material and methods: the pedagogical experiment was carried out on the basis of the Complex Children's Sports School No. 1, Kyivskyi District (Kharkov) among novice athletes 5-6 years old. The study involved 24 gymnasts: the control group $(n=12)$ conducted the training process according to the school program, experimental $(n=12)$ with the additional use of choreographic training. To evaluate the artistic and technical components, 2 choreographers with judicial experience and 4 trainers of the national category were involved. Because the level of preparedness of young athletes was at the initial stage, a 5-point assessment scale was applied. The first assessment of the basic exercises in rhythmic gymnastics among young athletes was carried out in the study groups at the beginning of the school year, the second - at the end of the half-year. Results: in the process of using choreographic exercises for mastering programs in rhythmic gymnastics for novice athletes 5-6 years old from the experimental group, reliably better assessment results were obtained in relation to the control group in performing the following components: "expressiveness of body movement" $(t=4.97 ; p<0.001)$, "balance" $(t=4.48 ; p<0.001)$, "character" $(t=$ 3.71; $p<0.01)$, "rhythm" ( $t=4.18 ; p<0.01)$, "jumping" $(t=3.22 ; p<0.01)$ and "turns" $(t=3.77 ; p<0.01)$. Conclusions: as a result of the research, it was found that the additional use of choreography in the training process of novice athletes of 5-6 years old effectively affects the performance of basic exercises in rhythmic gymnastics, which indicates the successful development of programs in this sport. It is during these classes that posture is formed, the musculoskeletal system is strengthened and the culture of movements of the gymnasts is formed.

Keywords: rhythmic gymnastics, choreography, novice athletes, artistic preparedness.

\title{
References
}

1. Bekina, S. I., Lomova, T. P., Sokovnina, E. N. (1983), Muzyka i dvizhenie (uprazhneniia, igry, i pliaski dlia detei 5-6 let) [Music and movement (exercises, games and dances for children 5-6 years old)]. Moskva: Prosveschenie, 208 p. (in Russ.).

2. Kyzim, P., Bateeva, N., (2021), «Improving the technical training of rhythmic gymnastics athletes by means of folk-stage dance», Slobozhanskii naukovo-sportyvnyi visnyk, No. 1(81), pp. 36-41, doi:10.15391/snsv.2021-1.005 (in Ukr.).

3. Lisitskaia, T. S. (1984), Horeografiia v gimnastike [Choreography in gymnastics]. Moskva: FIS, 175 p. (in Russ.).

4. Martynenko, O. V. (2008), Metodyka horeografichnoyi roboty z dit'my starshogo doshkil'nogo viku [Methodology for choreographic work with older preschool children]. Donetsk: TOV «Ugo-Vostok, LTD», 156 p. (in Ukr.).

5. Mullagil'dina, A. Y. (2016), «Improvement of artistry among qualified athletes in rhythmic gymnastics», Slobozhanskii naukovosportyvnyi visnyk, No. 4(54), pp. 79-83, doi:10.15391/ snsv. 4.014 (in Ukr.).

6. Tarakanova, A. P. (1996), "The system of choreographic education in schools and out-of-school educational institutions: Study guide». Kyyiv: Ministerstvo osvity Ukrayiny, 68 p. (in Ukr.). 
7. Rhythmic gymnastics (1999), Curriculum for children and youth sports schools, specialized schools of the Olympic reserve, schools of higher sports skills. Kyyiv, 115 p. (in Ukr.).

8. Rhythmic Gymnastics Competition Rules 2017-2020 (2017), Rhythmic Gymnastics Technical Committee, Federation International Gymnastics, 82 p. (in Russ.).

9. Riabchenko, O. V. (2015), «The formation of bases of culture of movement at children of 3-6 years old by means of rhythmic gymnastics», Slobozhanskii naukovo-sportyvnyi visnyk, No. 3 (47), pp. 80-81, doi.org/10.15391/snsv.2015-3 (in Eng).

10. Morgan, W. J. (2003), The Philosophy of Sport: A. Historical and Conoqtual Overview and Eric Dunning: handbook of Sports Studies, London: Sage, pp. 205-212 (in Eng).

11. Svobodovб, L., Skotбkovб, A., Hedbбvnэ, P., Vaculнkovб, P. \& Sebera, M. (2016), «Use of the dance pad for the development of rhythmic abilities», Science of Gymnastics Journal, Vol. 8 Issue 3, pp. 283-293 (in Eng).

12. Poliszczuk, R. (2003), Podstawy przygotowania choreograficznego w sporcie. Warszawa: Centralny Osrodek sportu, pp. 3238. (in Pol).

13. Kuzminska O. (1991), Podreczhik gimnasyki artystystycznej. Warszawa: Sport I Turystyka, 384 p. (in Pol).

Received: 20.05.2021.

Published: 23.06.2021.

\section{Відомості про авторів / Information about the Authors}

Рябченко Ольга Вікторівна: Харківська державна академія фізичної культури: вул. Клочківська 99, м. Харків, 61058, Україна.

Рябченко Ольга Викторовна: Харьковская государственная академия физической культуры: ул. Клочковская 99, г. Харьков, 61058, Украина.

Olga Riabchenko: Kharkiv State Academy of Physical Culture: 61058, Kharkiv, st. Klochkivska, 99, Ukraine.

ORCID: https://orcid.org/0000-0003-2868-0637

E-mail: riabchenko.ov@gmail.com 